\title{
Berenike Trogodytika: a Hellenistic fortress on the Red Sea coast, Egypt
}

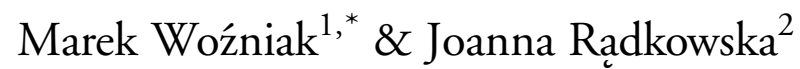

The ruins of Berenike Trogodytika have long attracted travellers searching for the remains of the famous Graeco-Roman port on the Red Sea. It was not until 2012, however, that the Berenike Project team were able to identify the location and size of the legendary Berenike of the Ptolemies.

Keywords: Egypt, Red Sea, Berenike, Hellenistic, Ptolemies

The ruins of ancient Berenike Trogodytika lie on the western coast of Egypt on the Red Sea. The Roman city was built on a fossil coral reef, quite possibly on top of the remains of the earlier, Ptolemaic settlement. Archaeological excavations by two teams, one Dutch-American from 1994-2001 and one Polish-American from 2008-2015, have demonstrated the existence of a major harbour at the site. From the first to second centuries $\mathrm{AD}$ there is evidence for commercial ties extending from Greece and Italy to South Arabia, India, the Malay Peninsula, Ethiopia and East Africa (Sidebotham et al. 2008; Sidebotham 2011).

The ruins of Berenike were discovered in 1818, but the remains of the Hellenistic city, which pre-dates the Roman harbour by some 300 years, were more thoroughly investigated in 2012 by the Polish-American team. Greater attention to the Early Hellenistic settlement was triggered by the results of a magnetic survey conducted in 1999 and 2000 and 20092010. Excavations over the next seasons identified a huge, multi-phased building (roughly $160 \mathrm{~m}$ long and $80 \mathrm{~m}$ wide) consisting of three large courtyards and several associated structures, forming an enclosed fortified complex of workshops and stores (Woźniak \& Radkowska 2014). A line of defences was located to the north and north-east of the 'fort' through the magnetic survey and confirmed by excavation (Figure 1).

These fortifications cut off the site from the mainland. A double line of walls protected the western part of the fortress, while a single line sufficed farther to the east and north (Figure 2). Square towers were built at the corners and in strategic places where sections of the walls connected.

The remains of living quarters and workshops were also located, as well as Hellenistic rubbish dumps, which yielded terracotta figurines, coins and a piece of the skull of a young elephant (a molar tooth from the same species was recovered from the northernmost of the two large courtyards inside the 'fort'). The most recent discovery is a fortified extension of the city

1 Polish Centre of Mediterranean Archaeology, University of Warsaw, Nowy Świat 4, Warsaw 00-497, Poland

2 Institute of Mediterranean and Oriental Cultures, Polish Academy of Sciences, Nowy Swiat 72, Warsaw 00-330, Poland

* Author for correspondence (Email:wozniakarcheo@gmail.com)

(C) Antiquity Publications Ltd, 2018

ANTIQUITY 92 366, e5 (2018): 1-7

https://doi.org/10.15184/aqy.2018.252 


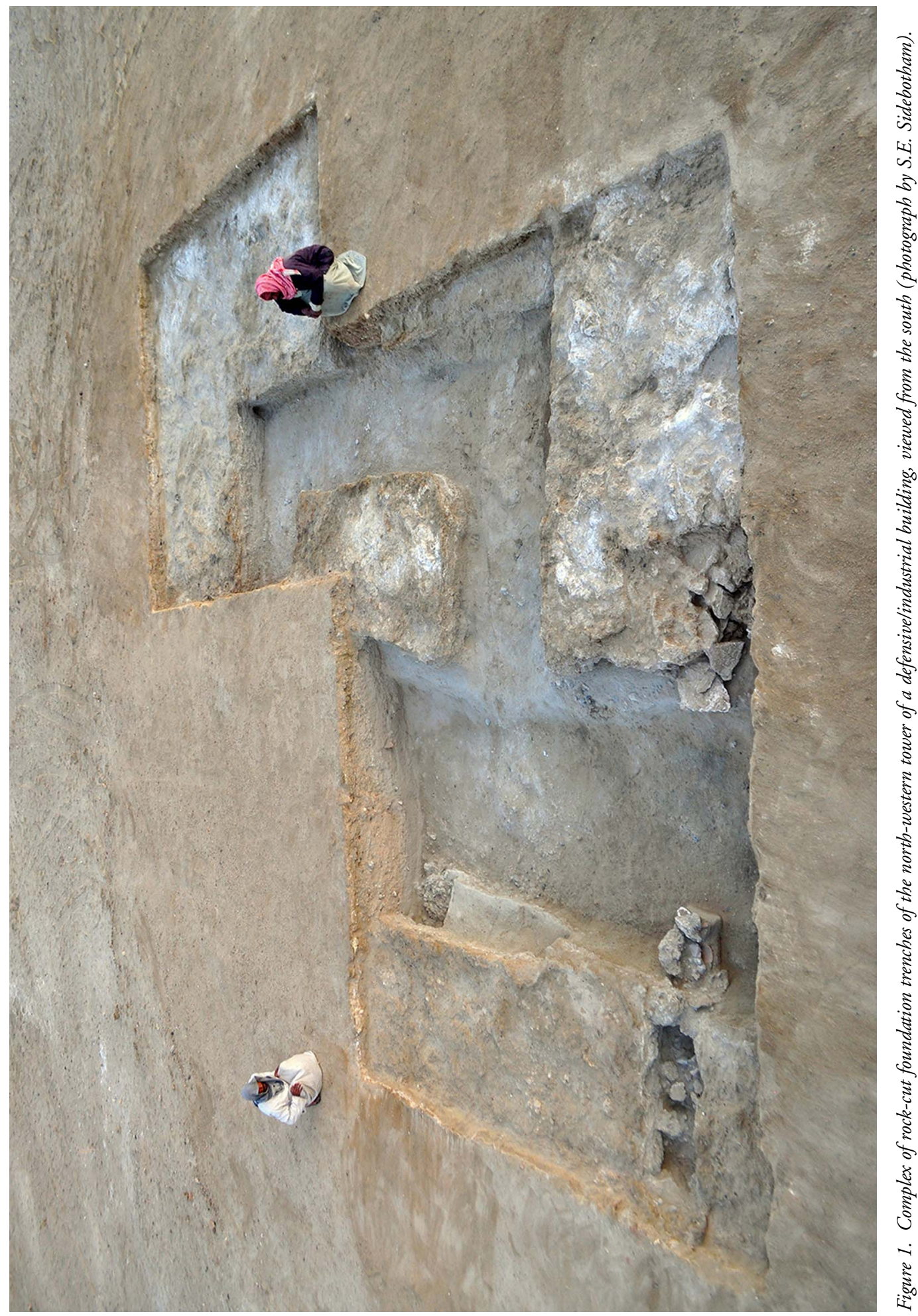

(C) Antiquity Publications Ltd, 2018 


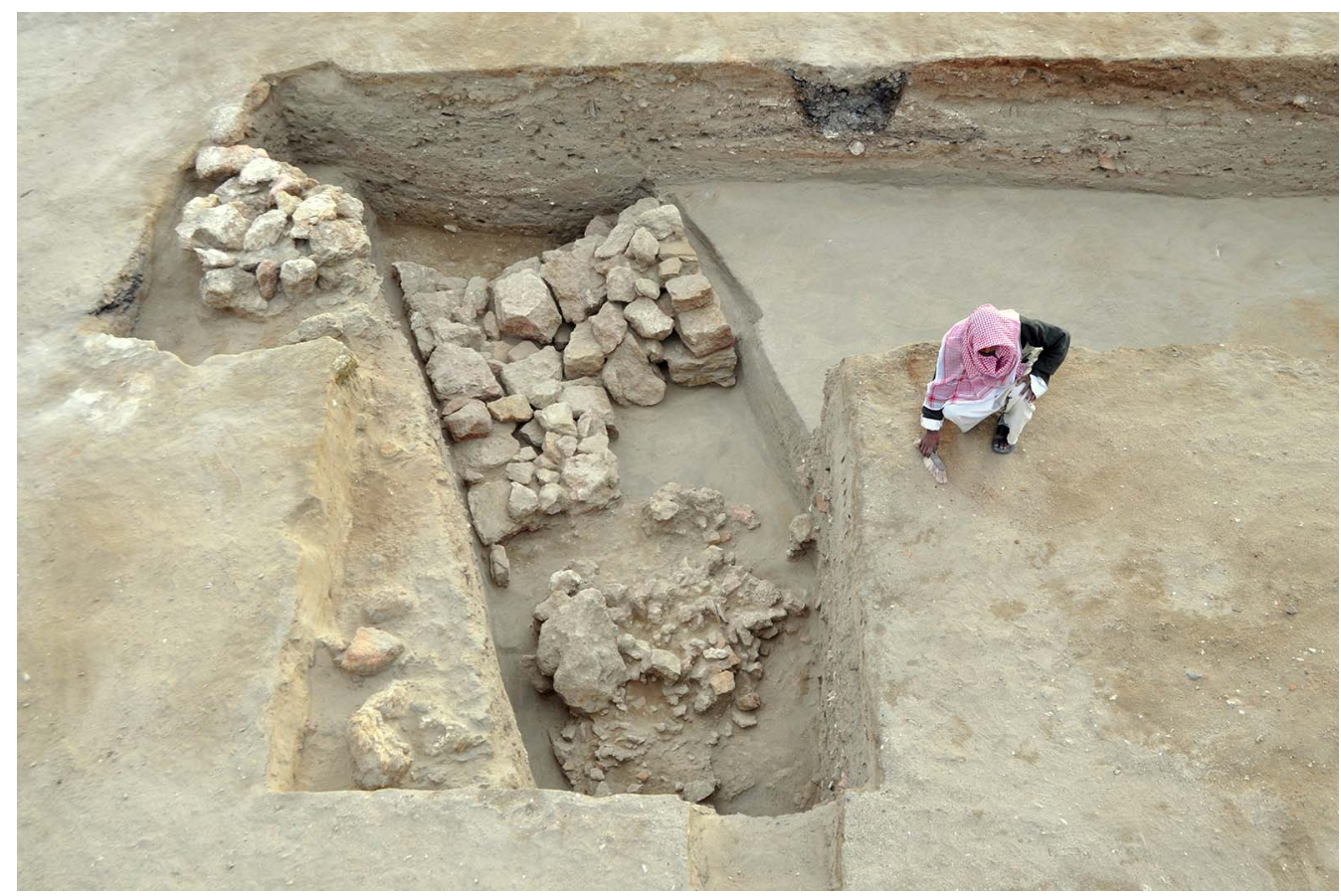

Figure 2. Uncovered fragment of the northern defensive wall of Berenike, viewed from the west (photograph by S.E. Sidebotham).

gate (Figure 3), dating to the third century BC and constructed over a complex of rock-cut wells: the only wells discovered in an ancient city on the Red Sea coast.

The second phase saw extension of the well's shape and narrow shaft into a rectangular, rock-cut chamber, which was more suitable for collecting the slowly flowing, potable water (Figures 4-5). A narrow rock-cut tunnel connected the well in the gate with an unexplored part of the building.

Water extracted from the well was distributed through a system of open pools located on the surface of the ground, south-west of the gate. The two largest pools may have had a total capacity of over 17000 litres. This area was clearly important for water storage-also indicated by the presence of installations for the drainage and collection of rainwater adjacent to the gatehouse to the east (Woźniak 2018: 49-59). The existence of such water-collecting installations demonstrates that there was sufficient rainfall to make collection worthwhile, suggesting a more humid climate than today.

The excavation of Hellenistic Berenike also yielded ecofacts that allow for a partial reconstruction of the economy of Hellenistic Berenike from the third to the first centuries BC (Figure 6). A considerable diversification of exploited food sources is suggested by substantial quantities of goat, sheep, cattle and pig bones discovered in the faunal material (examined by Marta Osypińska, Institute of Archaeology and Ethnology, Polish Academy of Sciences Poznań). Faunal remains also included numerous fish bones and the shells of edible mollusc 


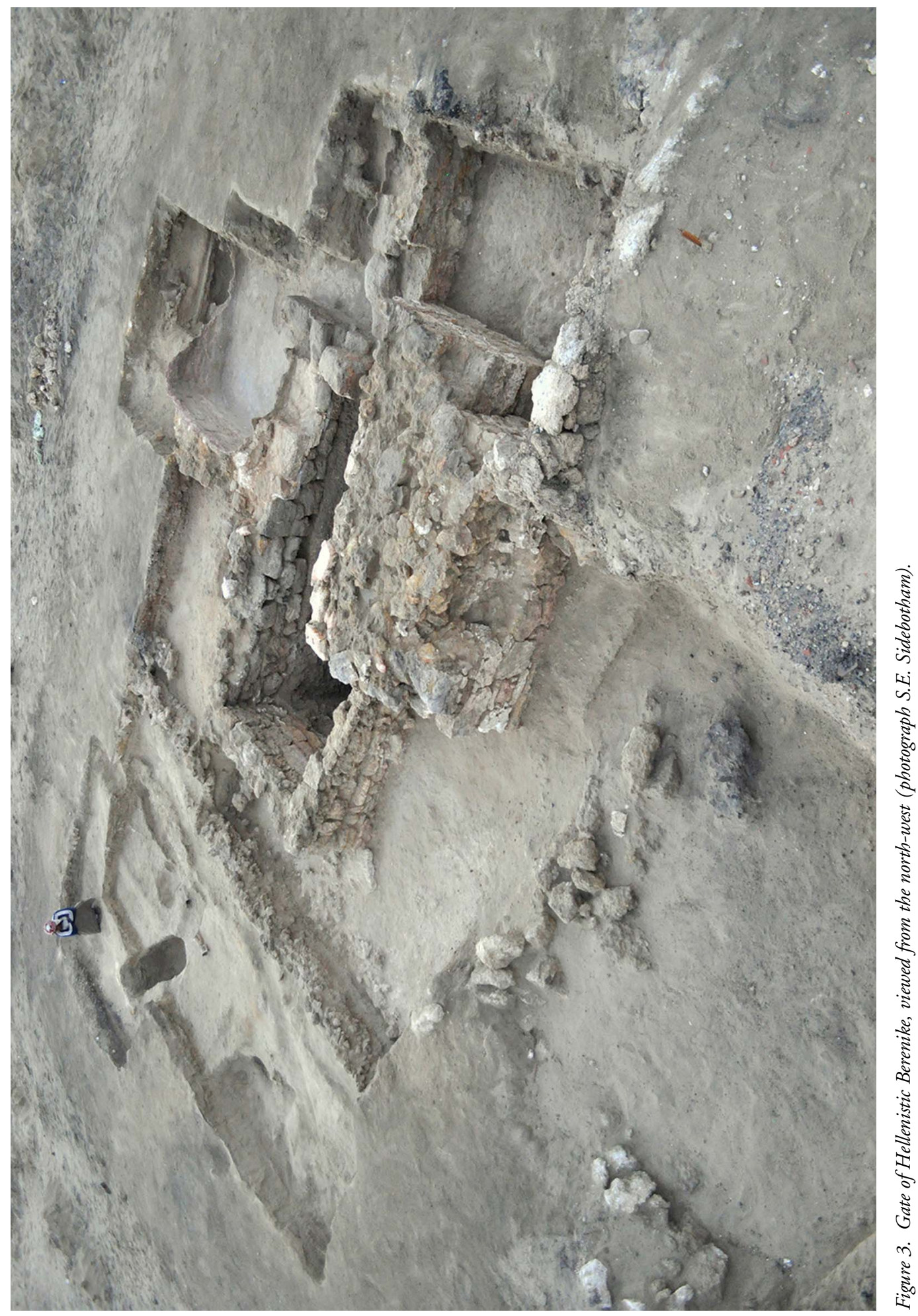

(C) Antiquity Publications Ltd, 2018 


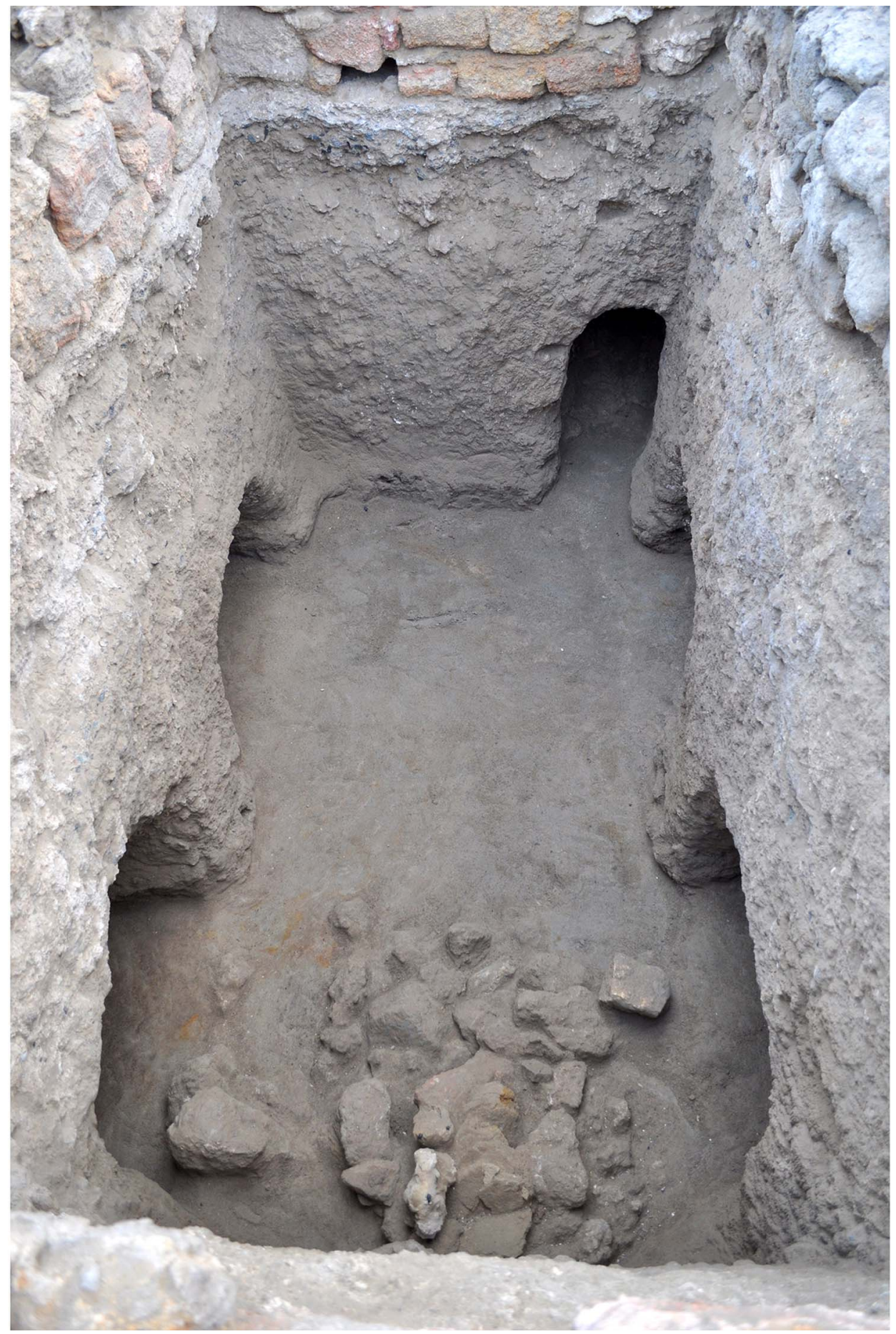

Figure 4. Internal chamber of the Hellenistic gate, showing the entrances of four rock-cut niches and the tunnel, viewed from the west (photograph by S.E. Sidebotham). 


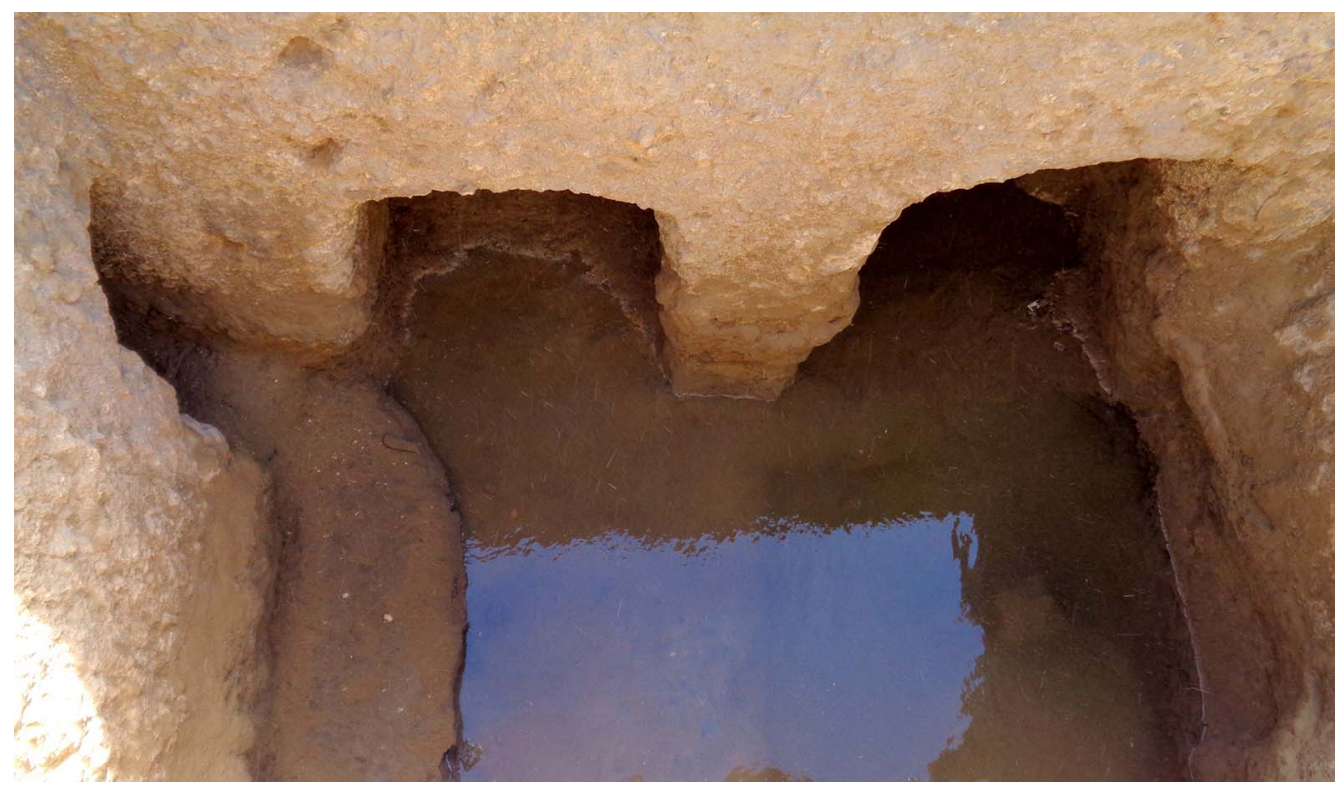

Figure 5. Water in the fully excavated chamber of the Hellenistic gate. On the right, the shape of the first phase of the well, viewed from the north (photograph by S.E. Sidebotham).

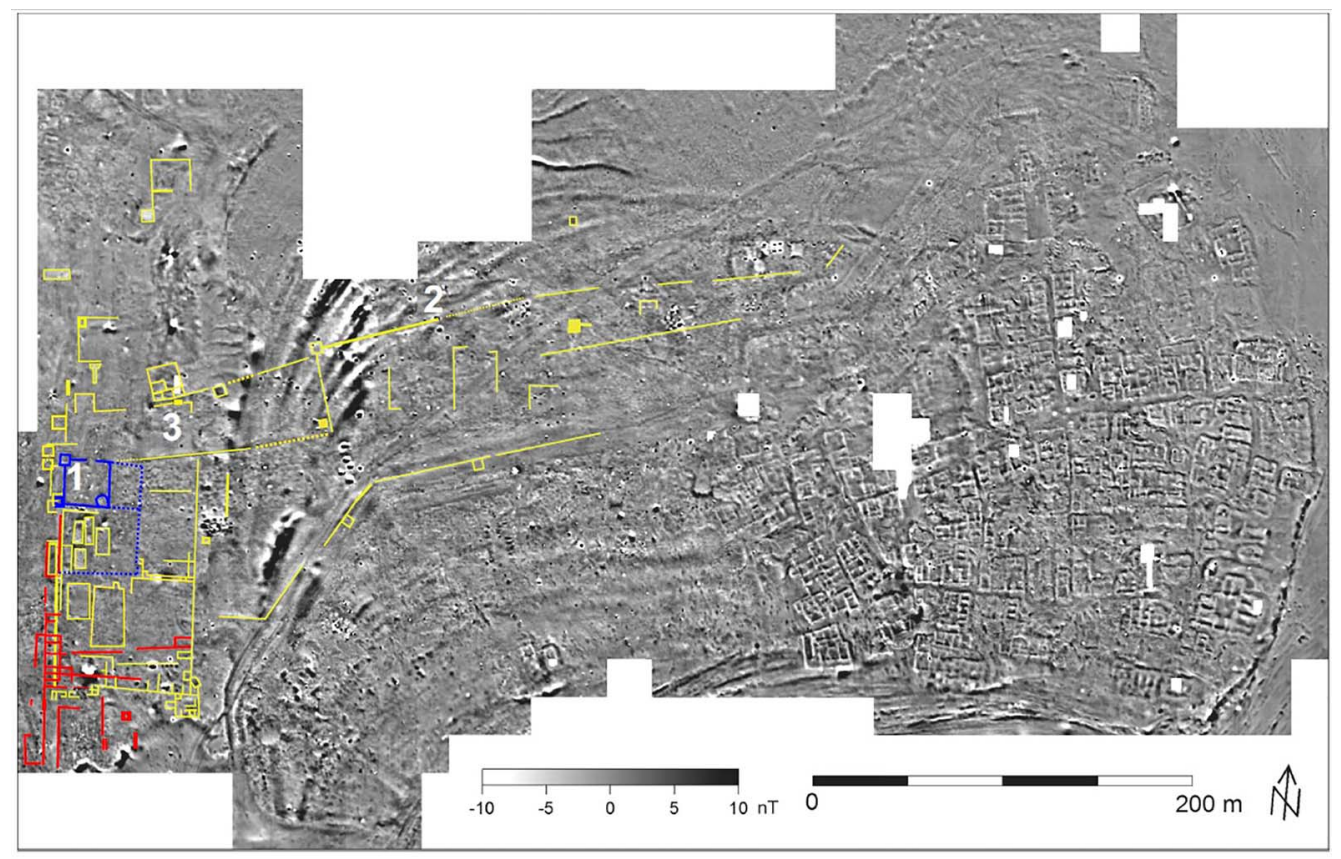

Figure 6. Hellenistic structures marked on the geomagnetic map: 1) the 'fort' with its three phases (blue: oldest; yellow: middle, main phase, joined with the city's fortifications; red: youngest); 2) northern defensive wall; 3) gate building (map by T. Herbich, interpretation by M. Wozniak \& J. Radkowska).

(C) Antiquity Publications Ltd, 2018 
species, including those restricted to mangrove habitats, which are not currently present in the Berenike area.

The architecture discovered in Berenike is the first-known example of Hellenistic urban architecture from the entire western coast of the Red Sea, as well as the only archaeologically investigated example of Hellenistic architecture from a city or port occupied during the Ptolemaic period in the Red Sea region.

\section{Acknowledgements}

A grant was provided by the National Science Centre (2015/17/N/HS3/00163).

\section{References}

Sidebotham, S.E. 2011. Berenike and the ancient maritime spice route. Oakland: University of California Press.

https://doi.org/10.1525/california/ 9780520244306.001 .0001

Sidebotham, S.E., M. Hense \& H.M. Nouwens. 2008. The red land. The illustrated archaeology of Egypt's eastern desert. Cairo: American University in Cairo Press.
WoźNIAK, M. 2018. Shaping a city and its defences: the fortifications of Hellenistic Berenike Trogodytika. Polish Archaeology in the Mediterranean 26(2): 43-60.

WoźNIAK, M. \& J.K. RądKowsKa. 2014. In search of Berenike of the Ptolemies. The Hellenistic fort of Berenike Trogodytika, its localization, form and development (part one). Polish Archaeology in the Mediterranean 23: 505-26. 